\title{
Analysis of Spray Characteristics and High Ambient Pressure in Gasoline Direct Injection using Computational Fluid Dynamics
}

\author{
Rozita Jumadi ${ }^{1}$, Amir Khalid ${ }^{1,}{ }^{*}$, Norrizam Jaat ${ }^{1}$, Iqbal Shahridzuan Abdullah ${ }^{1}$, Nofrizalidris Darlis ${ }^{1}$, \\ Bukhari Manshoor ${ }^{2}$, Azahari Razali², Azwan Sapit ${ }^{2}$, Ridwan Saputra Nursal ${ }^{1,3}$ \\ 1 Automotive and Combustion Synergies Technology Group, Faculty of Engineering Technology, Universiti Tun Hussein Onn Malaysia, 84600 \\ Pagoh, Johor, Malaysia \\ 2 Centre for Energy and Industrial Environment Studies, Faculty of Mechanical and Manufacturing Engineering, Universiti Tun Hussein Onn \\ Malaysia, Parit Raja, 86400 Batu Pahat, Johor, Malaysia \\ 3 Department of Marine Engineering, Politeknik Bagan Datuk, 36400 Hutan Melintang, Perak, Malaysia
}

\section{ARTICLE INFO}

\section{Article history:}

Received 18 March 2020

Received in revised form 17 May 2020

Accepted 22 May 2020

Available online 30 May 2020

\section{ABSTRACT}

The increase in population, the growth of the automotive industry and transportation sector led to a greater contribution of exhaust emissions, including from diesel and gasoline engines. This situation must be monitored in order to ensure that global air pollution can be minimised and at a safe level. For this reason, many technologies have been introduced as an alternative to reducing the exhaust emissions from the gasoline engine, one of which is the use of bio-petrol. Bio-petrol may be derived from agricultural crops, including conventional food plants or from special energy crops. The aim of this study is to investigate the effect of high ambient combustion chamber pressure of the gasoline engine on the spray characteristics by means of the computational fluid dynamics (CFD). For this study, the simulation works was carried out using ANSYS Fluent by considering the pressure base with absolute velocity formulation and steady state condition as well as using k-epsilon viscous model. The ambient pressures which are elevated from $0.6 \mathrm{MPa}$ to $1.6 \mathrm{MPa}$ with $0.2 \mathrm{MPa}$ increment step under the variant injection pressure and orifice diameter. The injection pressures are varied at 13,16 and $19 \mathrm{MPa}$, while the orifice diameter used in the CFD simulation are $0.22 \mathrm{~mm}$ and $0.263 \mathrm{~mm}$. The ambient temperature on the other hand is keep constant throughout the research. This simulation study found that the size of the cone spray angle is larger at high ambient pressure. Besides, the size of the cone spray angle is believed to be affected by the orifice diameter and injection pressure. In addition, the length of spray penetration is also increase as the ambient pressure elevated. This study can be further analysed by future researcher in finding the most efficient air-fuel mixture.

\section{Keywords:}

Ambient pressure; Bio-petrol;

\footnotetext{
* Corresponding author.

E-mail address: amirk@uthm.edu.my (Amir Khalid)
}

https://doi.org/10.37934/cfdl.12.5.3651 


\section{Introduction}

The Internal Combustion (IC) engine is classified as a thermal engine. Its cycle direction that was characterized by the output of work is the essential feature of the thermal engine. Apart from diesel fuel, gasoline or petrol fuel is the other commonly used fuel to run an IC engine specifically the gasoline engine. The gasoline engine which also known as the spark ignition (SI) engine is a type of internal combustion engine other than the compression ignition $(\mathrm{Cl})$ engine [1-5]. The presence of spark plugs in the construction of $\mathrm{SI}$ engine is vital as the ignition process will be carried out as soon as the spark ignites a mixture of fuel and air that were compressed inside the combustion chamber [6-8]. Gasoline which is also known as petrol is a type of flammable liquid that was derived from crude oil or petroleum. Crude oil is a type of limited non-renewable resources with a high complex mixture that composed from hydrocarbon and other organic matter deposits [9-11]. This oil will be going through specific refinement process before the standard gasoline oil is produced. Gasoline used in IC engine has significant effect in both environment; for example smog and human health by affecting the endocrine functions [12-14]. The negative impacts of it have been seen as one of the starting point to the introduction of bio-fuels.

A new concept of in-cylinder mixture formation which combines the best features for both the diesel and the gasoline engines is introduced to increase the efficiency of the fuel-air mixture, known as the gasoline direct injection (GDI) engine [15-16]. The direct injection method for GDI engine is done either through direct injection of liquid fuel or direct injection of pre-mixture injection [15-17]. GDI promotes numerous advantages that highly affect the performances of a vehicle even at standard ambient pressure. Vehicles that are occupied by GDI appear to have a higher power output compared to the other common carburettor and surprisingly more fuel efficient [18-19]. Besides, it can also accommodate alternative fuel, ensures drivability and smooth operation [19]. However, these advantages depend on the proper preparation of the air-fuel mixture and its distribution inside the chamber by the spray formation injected through the nozzle [20-21]. In a nutshell, the nozzle spray characteristics give the major significant to the combustion process of GDI engine.

Computational fluid dynamic (CFD) is a powerful tool in the form of software that provides platform to investigates the fluid flow, heat transfer and some other related phenomena like chemical reactions, using its analyser tools and simulation is carried out in computer [22-24]. It provides a wide range of applications in various sectors where it can be applied such as in marine hydrodynamics [24], vehicles and aircrafts for aerodynamics studies (e.g. drag and lift), turbo machinery for the flow movement inside the diffuser and rotating access, power-plant for combustion in gas turbines and in internal combustion engines, environmental engineering for the distribution of pollutants and effluents, and many more [23]. Therefore, this special tool might assist user to improve understanding on numerical analysis and algorithm, predicting the outcomes and shorten the development time needs regarding fluid flows [22-23]. In this study, the CFD simulation is applied to investigate the results on spray characteristics of fuel at variant ambient pressure under variant conditions. Different ambient pressure elevated from 0.6 MPa to $1.6 \mathrm{MPa}$ was considered in this study to analyse the effect of variant as well as high ambient pressure on spray characteristic in gasoline engine using CFD. Also, the ambient temperature on the other hand is kept constant at $300 \mathrm{~K}$ in the combustion chamber throughout the computational analysis. Other variable parameters such as the injection pressure and the orifice diameter are also taken into account in order to ensure that the comparison between the final results of this study can be compared with previous researches.

The numerical and computational study as a secondary approach may provide better and more comprehensive information on the impact on the spray characteristics under the operating condition of the engine. This will assist us in refining the correct method of mixing, ratio and injection as well 
as achieving lower emissions and more effective combustion. Therefore, this study is aim to investigate the effect of high ambient pressure using CFD which focusing on the spray characteristics of fuel combustion in gasoline engine. Results obtained from the CFD investigation is useful as reference for the purpose of comparing, assessing and verifying the experiment outcomes. In addition, the CFD simulation studies also offers less time consuming and also cost efficient.

\subsection{Ethanol}

Ethanol $\left(\mathrm{CH}_{3} \mathrm{CH}_{2} \mathrm{OH}\right)$ is a type of renewable fuel that was produced from various plants. Ethanol is a natural by-product of plant fermentation such as sugarcane, grain straw, maize and brown seaweed [4, 25-27]. The use of ethanol as fuel has shown potential in positive prospective in reducing the greenhouse gas emission, mainly due to the particles of the carbon dioxide $\left(\mathrm{CO}_{2}\right)$ which is part of the exhaust product for the ethanol combustion is absorbed by plants to help during photosynthesis. Blends of ethanol-gasoline are often used to operate on SI engine, however, vehicle have to undergo vehicle modification especially re-calibration on the carburettor and increased heating of the air fuel mixture as the properties of ethanol are different from gasoline [4, 25-26]. The comparison between ethanol and gasoline are tabulated and shown as in Table 1 [28-29].

Table 1

Comparison of various properties of gasoline and ethanol [28-29]

\begin{tabular}{lll}
\hline Properties & Ethanol & Gasoline \\
\hline Formula & $\mathrm{CH}_{3} \mathrm{CH}_{2} \mathrm{OH}$ & $\mathrm{C}_{7} \mathrm{H}_{16}$ \\
Density at $15^{\circ} \mathrm{C}\left(\mathrm{kg} \mathrm{m}^{-3}\right)$ & 795 & 750 \\
Viscosity at $20^{\circ} \mathrm{C}\left(\mathrm{mm}^{2} \mathrm{~s}^{-1}\right)$ & 1.52 & $0.4-0.8$ \\
Calorific value $\left(\mathrm{MJ} \mathrm{kg}^{-1}\right)$ & 26.4 & 43.3 \\
Octane number VM & 108 & 95 \\
Boiling Point $\left({ }^{\circ} \mathrm{C}\right)$ & 78 & $30-190$ \\
Vapour pressure $(\mathrm{kPa})$ & 16.5 & 75 \\
Oxygen content $(\% \mathrm{vol})$ & 34.7 & $<2.7$ \\
Carbon content $(\% \mathrm{wt})$ & 52.2 & 85.5 \\
Sulphur content $(\mathrm{ppm})$ & 0 & $\sim 200$ \\
\hline
\end{tabular}

\subsection{Spray Characteristics}

Two spray characteristics that were analysed in this study are spray tip penetration and spray cone angle. It can be affected by several factors such as the injection pressure, ambient condition (i.e. ambient pressure and ambient temperature), fuel type and the nozzle design [16]. The penetration of the spray tip equals to the distance of the spray formation from the tip of the injector nozzle to the tip of spray. Asides, the spray angle is measured from the outer to the centre edge of the spray [30].

\subsubsection{Spray tip penetration}

Spray tip penetration is measured from the tip of the nozzle to the tip of the spray, and this length is usually influenced by ambient pressure of combustion chamber $[16,30]$. The penetration of the spray nozzle at high ambient pressure, appears to be much shorter. Besides, the design of the injection nozzle and the injection pressure are among the factor that could influence the length of the spray formation. The spray tip penetration at lower ambient pressure might increasing rapidly 
compare to that at higher ambient pressure which primarily due to lower nitrogen density, therefore allowing the development of much longer spray penetration [16].

\subsubsection{Spray cone angle}

As the fuel leaves the orifice at high speed due to high injection pressure, the fluid flow splits into the ligaments and then into the droplets. In this, the spray takes the shape of a cone at a certain angle, and the liquid droplets occupy a considerable fraction of the gas volume in the chamber as illustrates in Figure 1. In the CFD analysis, the angle of the spray cone is achieved by taking measurements of two points at the periphery of the spray opening. Since this study was carried out under variant ambient pressure and injection pressure of pure gasoline and its blends, the measurement of spray cone angle was covering the wide range of ambient pressure from $0.6 \mathrm{MPa}$ to 1.6 $\mathrm{MPa}$. It is reported that higher ambient pressure could contribute a better vaporization while some previous studies exposed that ambient pressure has a greater impact on the spray cone angle than fuel injection pressure $[18,31]$. Aside, the presence of the ethanol volume fraction in the gasoline fuel it is believed to be one of factor that could also affect the spray cone angle [32].

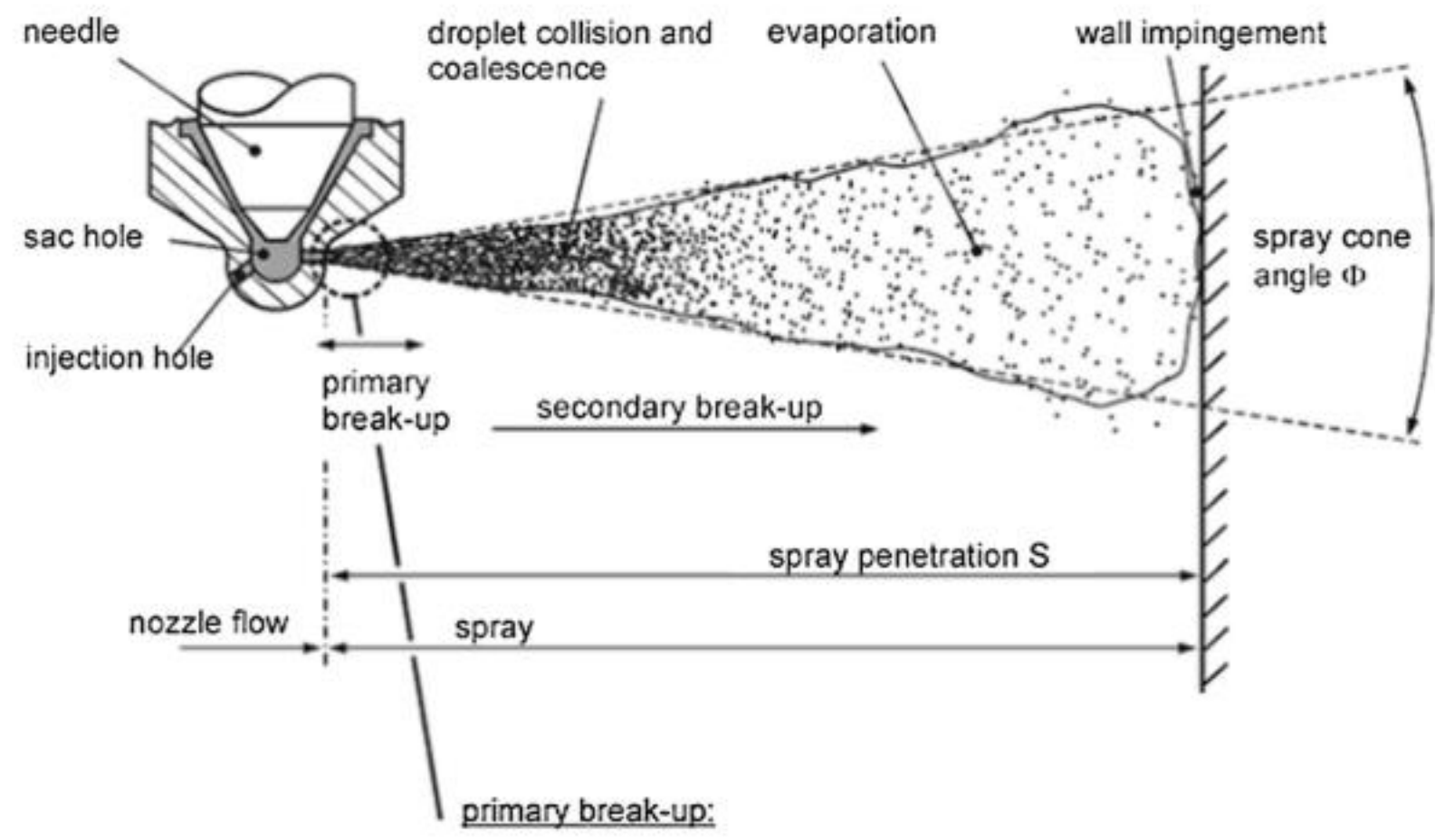

Fig. 1. Schematic of fuel spray through injector hole [15]

\section{Methodology}

Few studies have been conducted on recent decades to analyse the effect of ambient pressure on spray characteristics, internal fuel combustion and exhaust emission flow system [23, 33-34]. CFD is a special tool that provides platform to investigate and improve understanding on numerical analysis and algorithm, shorten the development time needs regarding fluid flows. It is comprehensively used in the prior stage of engine design which involve in selection of injection strategy [35]. This is due to the ability of to provide more detailed information on in-cylinder mixture formation and spray impingement through the CFD-based engine modelling [16, 22]. 
In this work, a fuel injector model associated with spray chamber has been prepared. The model was developed based on actual fuel injector component geometry used in gasoline engine in laboratory at particular scales. For this study, six different ambient pressure which stimulates at 0.6 $\mathrm{MPa}, 0.8 \mathrm{MPa}, 1.0 \mathrm{MPa}, 1.2 \mathrm{MPa}, 1.4 \mathrm{MPa}$ and $1.6 \mathrm{MPa}$ are used to analyse the impact of high ambient pressure on fuel spray characteristic in gasoline engine by means of CFD. Other parameters such as the injection pressure and the orifice diameter are also set at different value to ensure that the final results of this computational study can be compared with previous researches. The injection pressures are set at three different parameters which are $13 \mathrm{MPa}, 16 \mathrm{MPa}$ and $19 \mathrm{MPa}$. In addition, the parameters for the orifice diameter that used in the CFD simulation are $0.22 \mathrm{~mm}$ and $0.263 \mathrm{~mm}$. The ambient temperature on the other hand is kept constant at $373 \mathrm{~K}$ in the combustion chamber throughout the research. The parameter conditions and boundary conditions that used in ANSYS Fluent simulation work is detailed in Table 2. Asides, the flow chart for the Computational Fluid Dynamics (CFD) simulation process methodology is shown in Figure 2.

Table 2

\begin{tabular}{lll} 
Parameter conditions for ANSYS Fluent test & \\
\hline General & $\begin{array}{l}\text { Pressure based with } \\
\text { absolute velocity } \\
\text { formulation }\end{array}$ & Steady state \\
\hline Model & Species transport & Bio-petrol \\
Viscous & k-epsilon & Realizable \\
Material & Air & Bio-petrol \\
Boundary Condition & Air inlet = pressure & Fuel inlet = pressure \\
& Ambient temperature & $373 \mathrm{~K}$ \\
& Orifice diameter & $0.22 \mathrm{~mm}$ \\
& & $0.263 \mathrm{~mm}$ \\
& & $0.6 \mathrm{MPa}$ \\
& & $0.8 \mathrm{MPa}$ \\
& & $1.0 \mathrm{MPa}$ \\
& Ambient pressure & $1.2 \mathrm{MPa}$ \\
& & $1.4 \mathrm{Mpa}$ \\
& & $1.6 \mathrm{MPa}$ \\
& & $13 \mathrm{MPa}$ \\
& & $16 \mathrm{MPa}$ \\
& & $19 \mathrm{MPa}$ \\
\hline
\end{tabular}

The spray injector was designed to be concentrated on the injector head and the spray chamber using a 3D developer software package. A finished spray injector has six symmetry nozzle holes with an angle of 60 degrees between each hole. Thus, this study will only focus on one out of six holes designed to be less time-consuming, and will also help minimise any possible error during simulation. Figure 3 depicts the geometry for $1 / 6$ part of nozzle injector. Meanwhile, Figure 3 and Figure 4 show the injector nozzle of gasoline engine which linked to the spray chamber.

Pre-processing, solver and post-processing are the three main processes involved in CFD analysis. By means of ANSYS Fluent solver, the simulation works begin with the pre-processing step in the development of a solver followed by post-processing, where the results of the analysis are reviewed by generating graphical applications, animations and reports. The outcomes of the simulated tests shall be used to examine and evaluate the characteristics of the spray. 


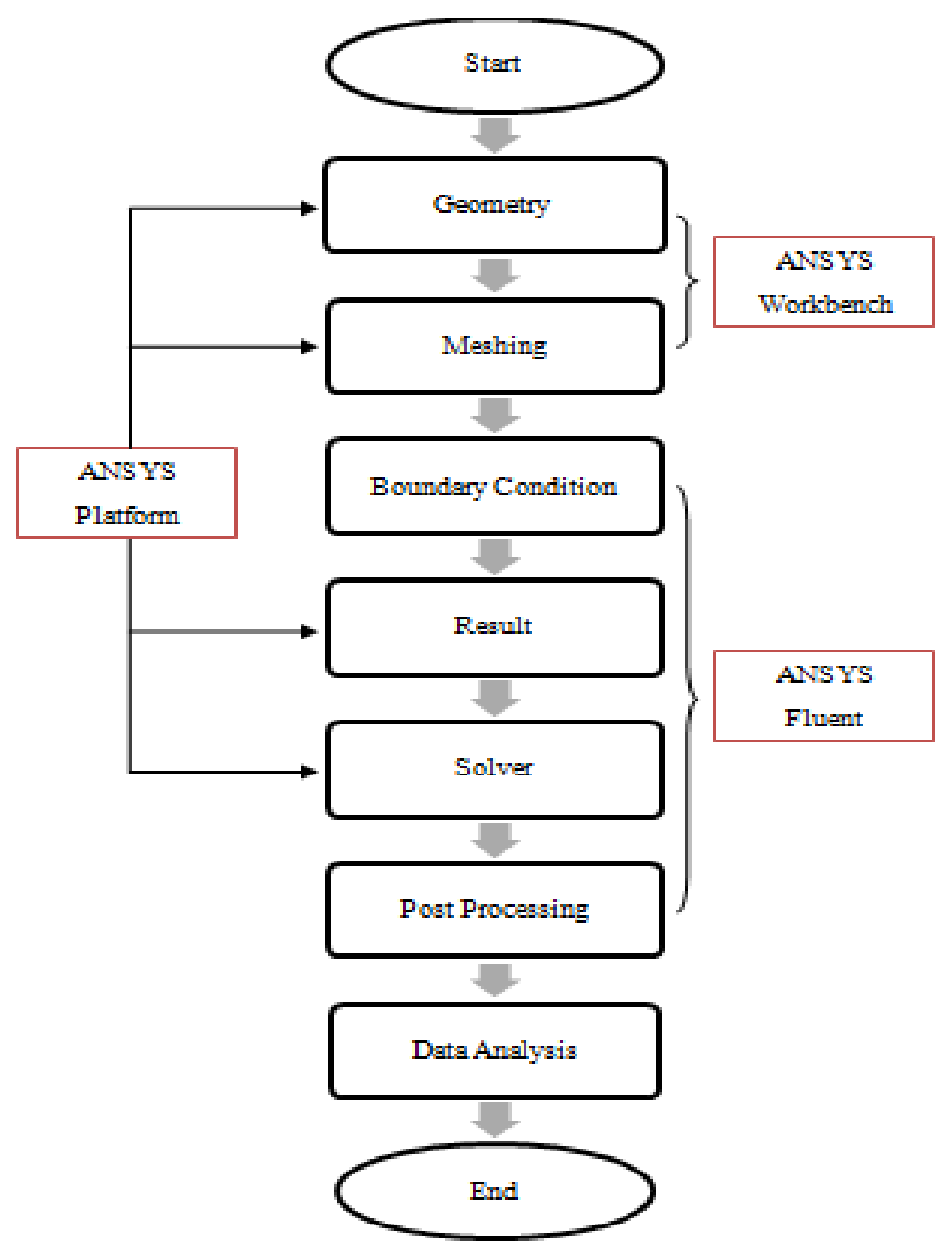

Fig. 2. CFD simulation process flow chart

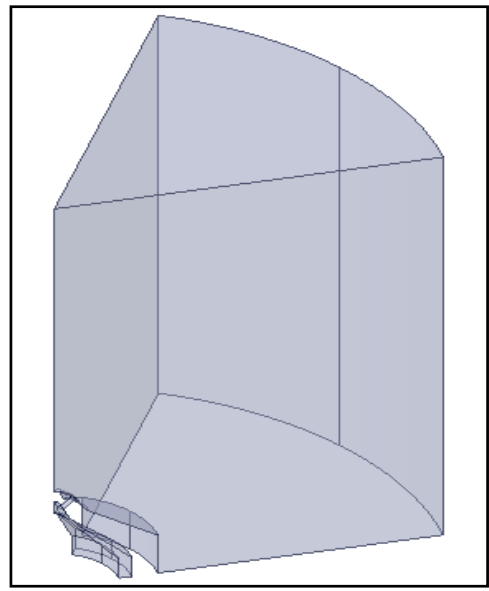

Fig. 3. Model of injector and spray chamber

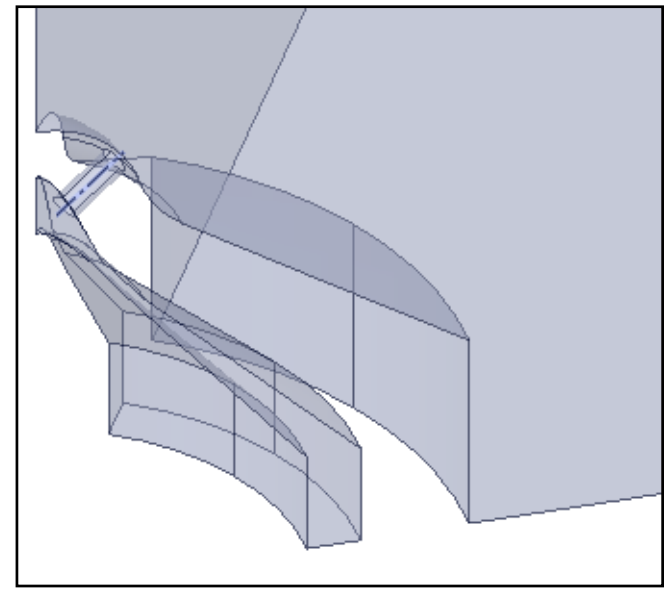

Fig. 4. The injector nozzle connected to the spray chamber

\subsection{Grid Independence Test and Validation Process}

Pre-processing is a stage of using boundary condition to generate output. This output will later use an input by another program. ANSYS Workbench environment has brought connectivity, geometry clean-up tools automatic meshing, extensive meshing tools to improve performance and quick simple definition of initial and boundary conditions. In order to stimulate the geometry build, 
set the parameters and the cross-section of the model or drawing. Solver is a software that used to solve mathematical problems generated within the pre-processor and data results to satisfy the finite element analysis. It is an unstructured framework finite volume Euler solver in 3D mathematical statements or equations for a compressible flow. In this study, the ANSYS Fluent software will work as a solver during the simulation process as it has the ability to analyze the change at any time. Besides that, it also time-efficient in getting the time to calculate the analysis needed. This is due to the implementation of the Graphical User Interface (GUI) which helps to shorten the processing time and improve the time taken in the development of the model. In addition to that, ANSYS Workbench solver software play roles in assuming important part in simulation by defining the type and analysis option, specify boundary condition, also identify the upshot of the simulation.

Post processing is a process of reviewing the results of an analysis by generating graphic applications, animations and reports. This step helps in analyzing the results obtained from the simulation conducted. It is a vital step as it impact could affect ones to understand on how the parameters applied could affect the design of a model constructed. By using post-processing, visual impact after simulation can be seen through the shaded and transparent surfaces, path lines, vector plots, contour plots, custom field variable definition and scene construction also various stresses such as stress, stress contour and principal stresses. Post-processing also includes importing data simulation also its solution from ANSYS Fluent accordingly to suitable post-processing tool such as ANSYS CFD-post, third party graphics and ANSYS Workbench CFD simulation for more detail analysis and solution. Besides, ANSYS Fluent can outline structural and thermal loads on surfaces and temperatures from ANSYS Fluent to third party graphics when it is standalone mode in volume.

Computational Fluid Dynamics (CFD) illustrate the flow of fluid at discrete point in the flow by using the finite element method. Discrete point which also known as grid or mesh provide significant effect to the accuracy of the data solution. It is important to model by following its accurate geometry as any error could give an impact to the solution. The effective grid size means it is small enough to minimize errors from dissipation due to grid and big enough to save computing source. There are few steps of meshing the geometry after modelling a model. Start by selecting all surfaces of a spray injector and chamber. This step is also called face meshing. Check all selected surfaces of the model to make sure everything done properly in order to obtain perfect meshing. Then, proceed with the volume meshing by meshing with appropriate type of mesh. Figure 5 and 6 show the meshing of injector and spray chamber and meshing of injector with nozzle connected to the spray chamber, respectively.

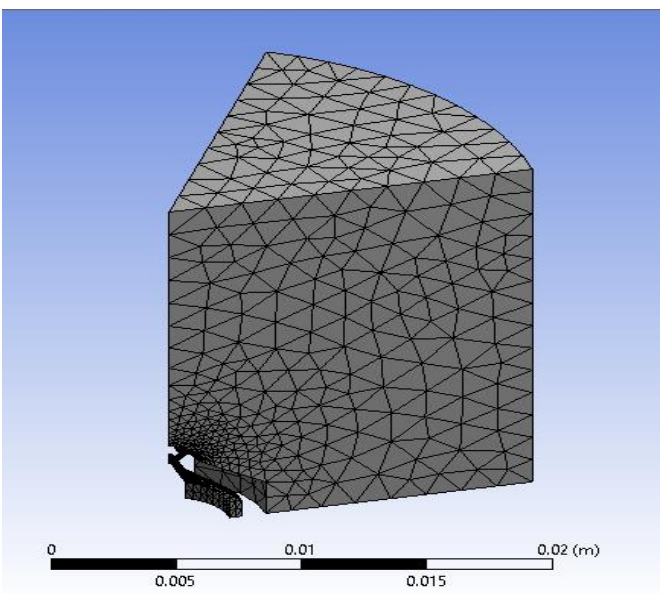

Fig. 5. Meshing of injector and spray chamber

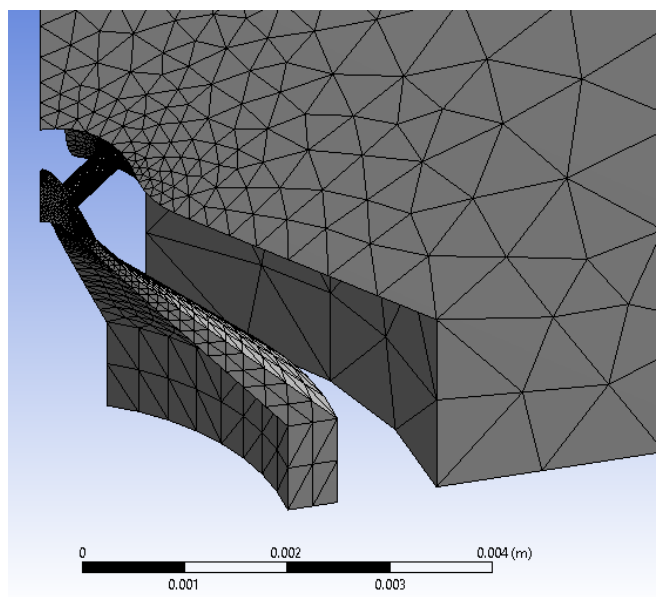

Fig. 6. Meshing of injector with nozzle connected to the spray chamber 


\section{Results and Discussion}

The results were simulated at different ambient pressures which are $0.6 \mathrm{MPa}, 0.8 \mathrm{MPa}, 1.0 \mathrm{MPa}$, 1.2 $\mathrm{MPa}, 1.4 \mathrm{MPa}$ and 1.6 MPa. Besides, the injection pressures are also set at three different pressures which are $13 \mathrm{MPa}, 16 \mathrm{MPa}$ and $19 \mathrm{MPa}$. The other parameters were kept constant where the ambient temperature at $373 \mathrm{~K}$. The fuel was injected through six-hole injector with two different holes diameter of $0.22 \mathrm{~mm}$ and $0.263 \mathrm{~mm}$.

\subsection{Effect of Ambient Pressure on Velocity Start Point}

The velocity start point of fuel injection in the chamber at different ambient pressure was tabulated into Table 3. Separately, the values for each of the velocity were plotted into graphs as shown in Figure 7. By referring to the graph, it can be seen that the velocity start point almost similar for all ambient pressure with all of the velocity demonstrates a declining trends over the range of ambient pressure. Therefore, the lowest velocity start point is found at the highest ambient pressure which is $1.6 \mathrm{MPa}$ at injection pressure of $19 \mathrm{MPa}$ for both orifice diameters. The reason for this condition is primarily due to the high ambient pressure restrict the material from travelling in much faster rate. In conjunction, the results also remark the increment of velocity proportional to the injection pressure. Besides, different diameter of nozzles also contributed much to these changes. This results also can be proved through the fluid dynamics theory on how an area or diameter affecting the velocity where the theory stated that if the inside diameter is increase, the flow area and liquid velocity will be increases, while the head loss due to friction will decreases.

Table 3

Velocity at start point of fuel injection in chamber

\begin{tabular}{lllllll}
\hline \multirow{2}{*}{ Parameter } & \multicolumn{2}{l}{$0.22 \mathrm{~mm}$} & \multicolumn{5}{l}{$0.263 \mathrm{~mm}$} \\
& $13 \mathrm{MPa}$ & $16 \mathrm{MPa}$ & $19 \mathrm{MPa}$ & \multicolumn{4}{l}{$13 \mathrm{MPa}$} & $16 \mathrm{MPa}$ & $19 \mathrm{MPa}$ \\
\hline \multirow{5}{*}{0.6} & 4.67046 & 5.20047 & 5.68335 & 4.52707 & 5.04241 & 5.51005 \\
0.8 & 4.63395 & 5.16638 & 5.65241 & 4.49007 & 5.01025 & 5.48008 \\
1.0 & 4.59586 & 5.13265 & 5.62204 & 4.45383 & 4.97734 & 5.45007 \\
1.2 & 4.55692 & 5.09897 & 5.59038 & 4.41629 & 4.94394 & 5.41983 \\
1.4 & 4.51862 & 5.06475 & 5.55914 & 4.37928 & 4.91027 & 5.38935 \\
1.6 & 4.48050 & 5.02973 & 5.52714 & 4.34122 & 4.87706 & 5.35884 \\
\hline
\end{tabular}

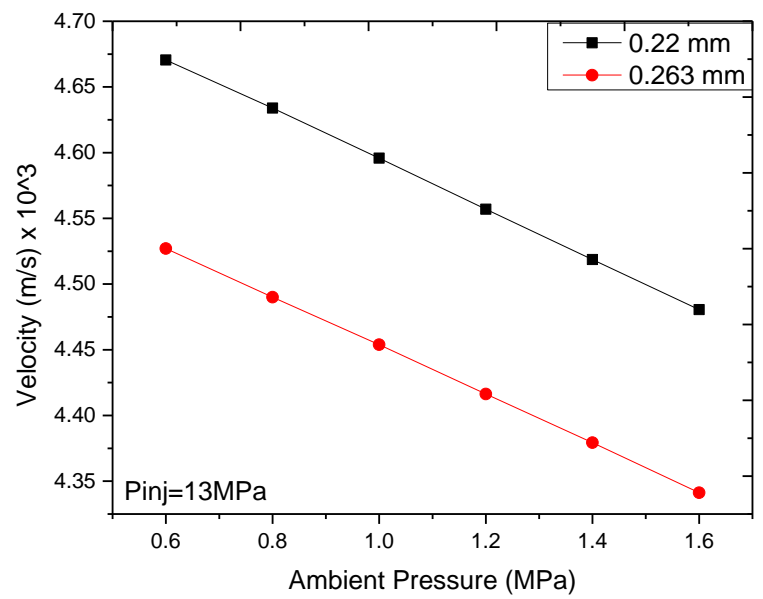

(a) 


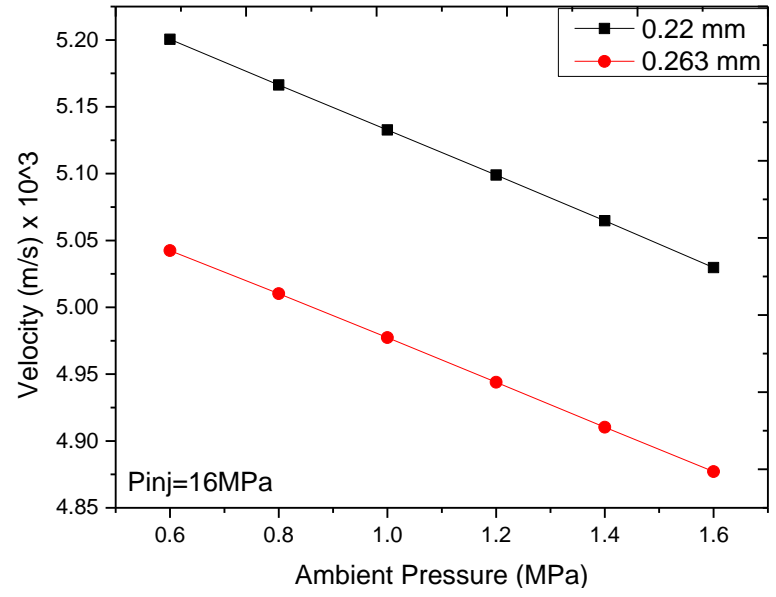

(b)

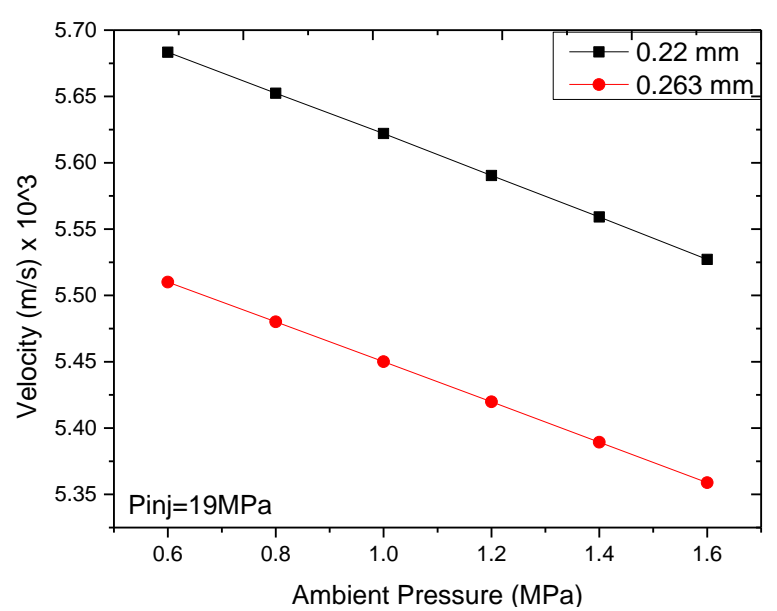

(c)

Fig. 7. Effect of ambient pressure on velocity start point at different orifice diameter and injection pressure. Injection pressure of: (a) $13 \mathrm{MPa}$ (b) $16 \mathrm{MPa}$ (c) $19 \mathrm{MPa}$

\subsection{The Effect of Ambient Pressure at Different Injection Pressure on Spray Penetration}

The differences in spray characteristic at different ambient pressure were much clearly be seen by varying the injection pressure that was injected into the combustion chamber. For that, three different injection pressures were set at three different ambient pressures. The quantitative results for the simulation are shown in Figure 8. The spray penetration was measured starting from the injector nozzle tip until the spray tip as shown in Figure 8. The penetration of the spray is required to be measured in order to gain the value and plot the data as in Figure 9.

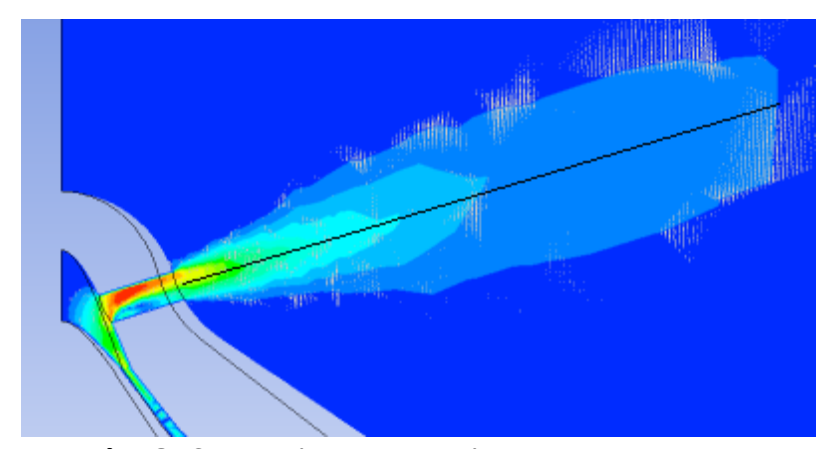

Fig. 8. Spray tip penetration measurement

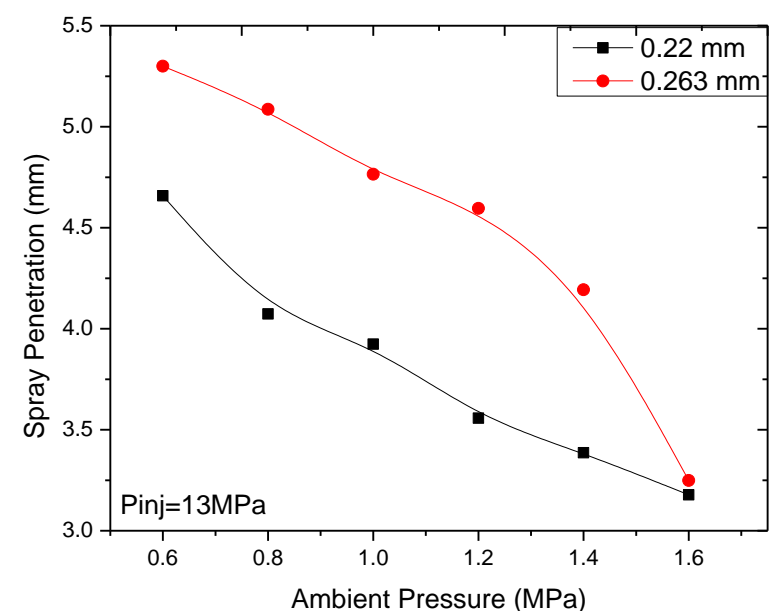

(a) 


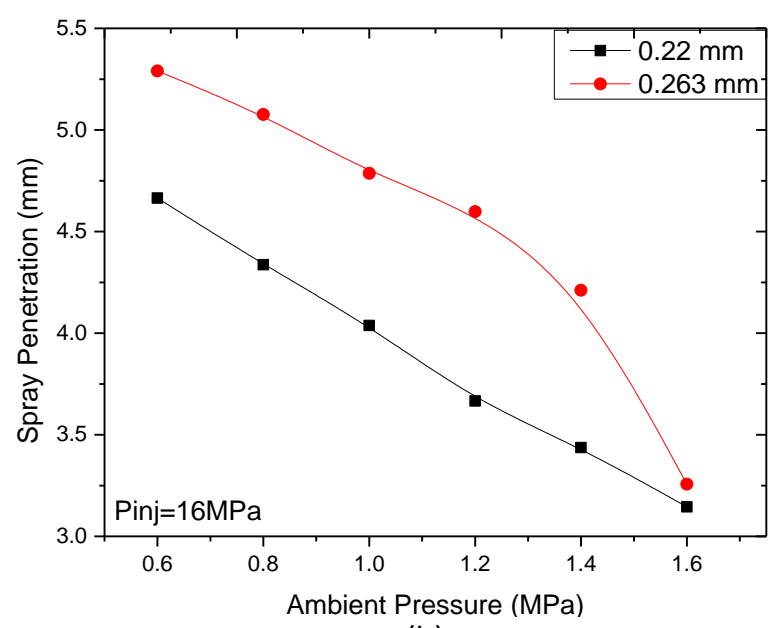

(b)

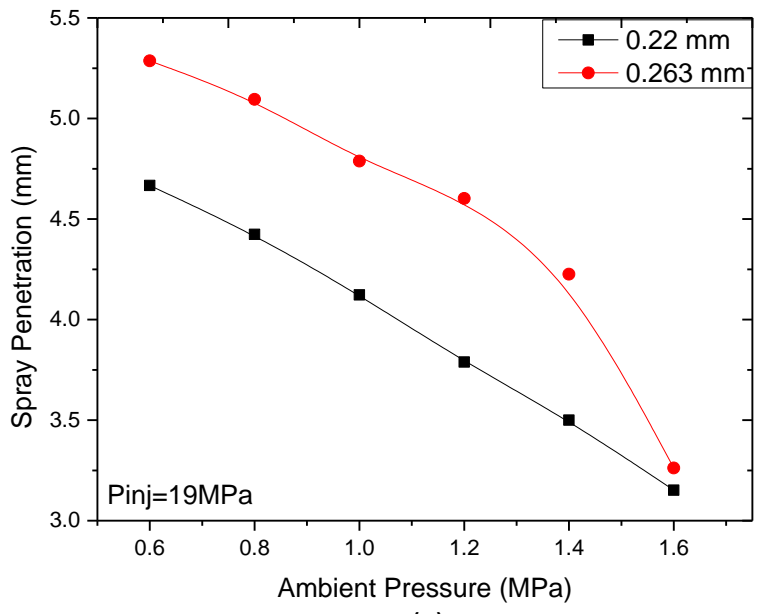

(c)

Fig. 9. Effect of ambient pressure on spray penetration at different injection pressure. Injection pressure of: (a) $13 \mathrm{MPa}$ (b) $16 \mathrm{MPa}$ (c) $19 \mathrm{MPa}$

Figure 9 clearly shows that variations of spray characteristic were produced as the ambient pressure and the injection pressure increased. The spray penetrations were measured at variant ambient pressure and injection pressure. From the result, the highest spray penetration is observed when the ambient pressure is at the lowest value. The penetration is ranging approximately from 4.5 $\mathrm{mm}$ to $5.5 \mathrm{~mm}$ at all injection pressure. On the contrary, three lowest spray penetrations were measured at high ambient pressure with the total of $3.178 \mathrm{~mm}, 3.145 \mathrm{~mm}$ and $3.152 \mathrm{~mm}$ with respect to $13 \mathrm{MPa}, 16 \mathrm{MPa}$ and $19 \mathrm{MPa}$ injection pressure accordingly.

\subsection{The Effect of Ambient Pressure at Difference Orifice Diameter on Spray Penetration}

High ambient pressures at different orifice diameters were also studied in order to investigate its effect on the spray penetration. Figure 10 depict all values of spray penetration at two different nozzle diameters which are $0.22 \mathrm{~mm}$ and $0.263 \mathrm{~mm}$ with six different ambient pressures of $0.6 \mathrm{MPa}$, 0.8 MPa, 1.0 MPa, 1.2 MPa, 1.4 MPa and 1.6 MPa. The figure shows that the increasing of ambient pressure at two different orifice diameter causing the spray penetration to decrease. High ambient pressure will cut down the ability of the spray to penetrate much longer and thus, resulting in shorter penetration of spray injected. The maximum penetration reached at $0.22 \mathrm{~mm}$ orifice diameter is slightly shorter if being compared to the $0.263 \mathrm{~mm}$ nozzle diameter. The longest penetration is at $0.263 \mathrm{~mm}$ orifice diameter with $0.6 \mathrm{MPa}$ ambient pressure at all injection pressure with the value approximately above $5.3 \mathrm{~mm}$. It is also found out that with the decrease of the orifice diameter, the spray penetration decreases. This can be proved by looking at figure attached below where the spray penetration becoming much shorter when the orifice diameter reduced from $0.263 \mathrm{~mm}$ to $0.22 \mathrm{~mm}$ at the same ambient pressure which is equal to $1.6 \mathrm{MPa}$. Larger orifice diameter allows more fuel to be injected which makes it hard for the ambient pressure to resist the penetration which then allowing the spray penetration increase its value. 


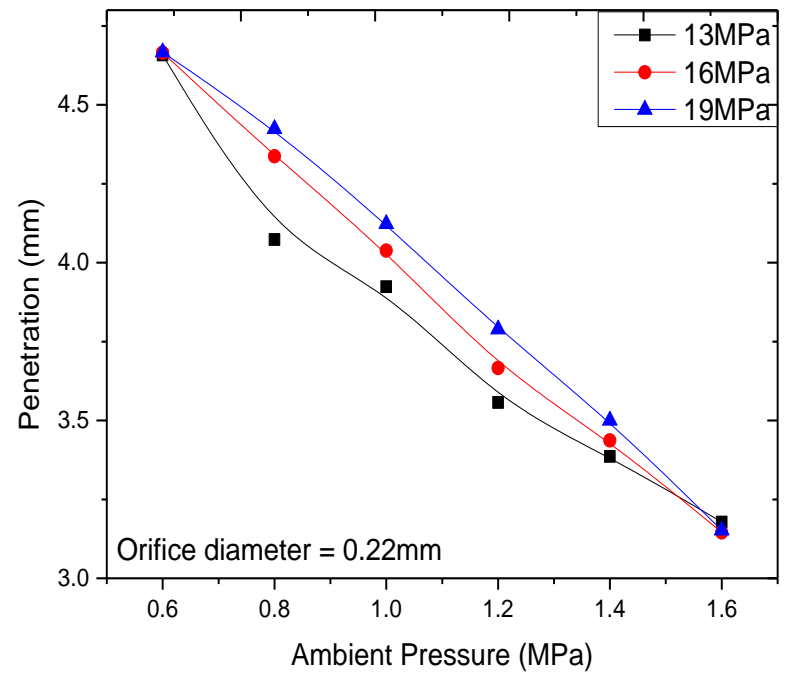

(a)

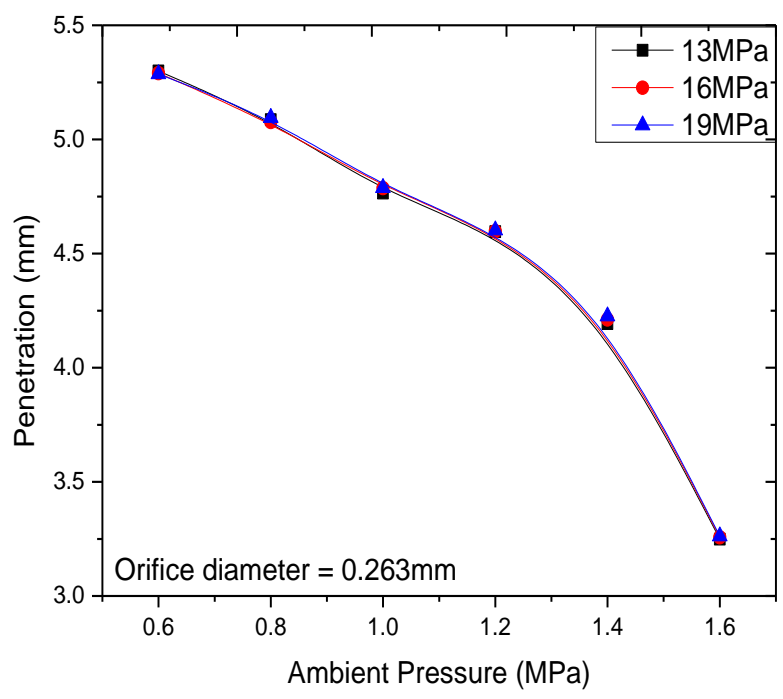

(b)

Fig. 10. Effect of ambient pressure on spray penetration at different orifice diameters. Orifice diameters of: (a) $0.22 \mathrm{~mm}$ (b) $0.263 \mathrm{~mm}$

\subsection{The Effect of Ambient Pressure at Difference Injection Pressure and Orifice Diameter on Spray Formation}

Previous studies show that the ambient pressure affects most on the formation of the spray cone angle. The spray cone angle is the spray shape injected by the nozzle into the chamber. It was measured by from one to the other outer edge of the spray. The example of the measurement of the spray cone angle is shown in Figure 11. The figure shows that the measurement is taken from the top view of the model. A straight line at the centre of the spray angle is used as the reference line. Lines at both edge of the spray indicate the maximum cone angle achieved by the spray. For this study, the results for the spray cone angle were not significant as there are only little changes at every different ambient pressure used and therefore, it is not discussed in more detail. Separately, the simulation results between the spray cone angles through various ambient pressure for orifice diameters of 0.22 $\mathrm{mm}$ and $0.263 \mathrm{~mm}$ can be seen in Table 4 and Table 5 respectively. Both tables show that the spray cone angle is wider for the bigger orifice diameter for all simulation test. The combination of ambient pressure and injection pressure also plays a significant role in determining the size of the cone angle. At high injection pressure and ambient pressure, the size of the spray angle decreased accordingly.



Fig. 11. Spray cone angle measurement 
On the other hand, the spray penetration is also affected as the ambient pressure elevated to a certain value. When the ambient pressure it set to the maximum value which is at $1.6 \mathrm{MPa}$, the observation from figures in Table 4 and Table 5 displays the penetration of spray for all injection pressure condition are shortest than of the rest of ambient pressure condition. This effect is occurred due to higher ambient air density as a result of higher ambient pressure that leads to the increasing of frictional resistance of spray molecules and droplets, and therefore resulting in restriction of droplets collision and decreasing of axial penetration. In spite of that, higher injection pressure will saturate the ambient pressure effect thus causing the spray to penetrate longer. This effect can be observed at figures for both spray formation through injector hole with orifice diameter of $0.22 \mathrm{~mm}$ and $0.263 \mathrm{~mm}$. At ambient pressure of $1.6 \mathrm{MPa}$, the spray spread the shortest penetration among all ambient pressure and all injection pressure tested condition. Apart from that, it can be seen that the longest or deepest spray penetration demonstrated at the lowest ambient pressure simulation test. As for the ambient pressure at different orifice diameter, it has been found that the spray penetration degrades the at $0.22 \mathrm{~mm}$ orifice diameter at all elevated ambient pressure compared to when it applied the $0.263 \mathrm{~mm}$ orifice diameter. This is because of the smaller area that resulting in high resistance which at the end prevent the spray to extend more. Therefore, it can be concluded that the penetration of the gasoline fuel spray is shortened through the smaller orifice diameter of the injector and at higher ambient pressure.

Table 4

Spray formation at variant conditions with $0.22 \mathrm{~mm}$ orifice diameter

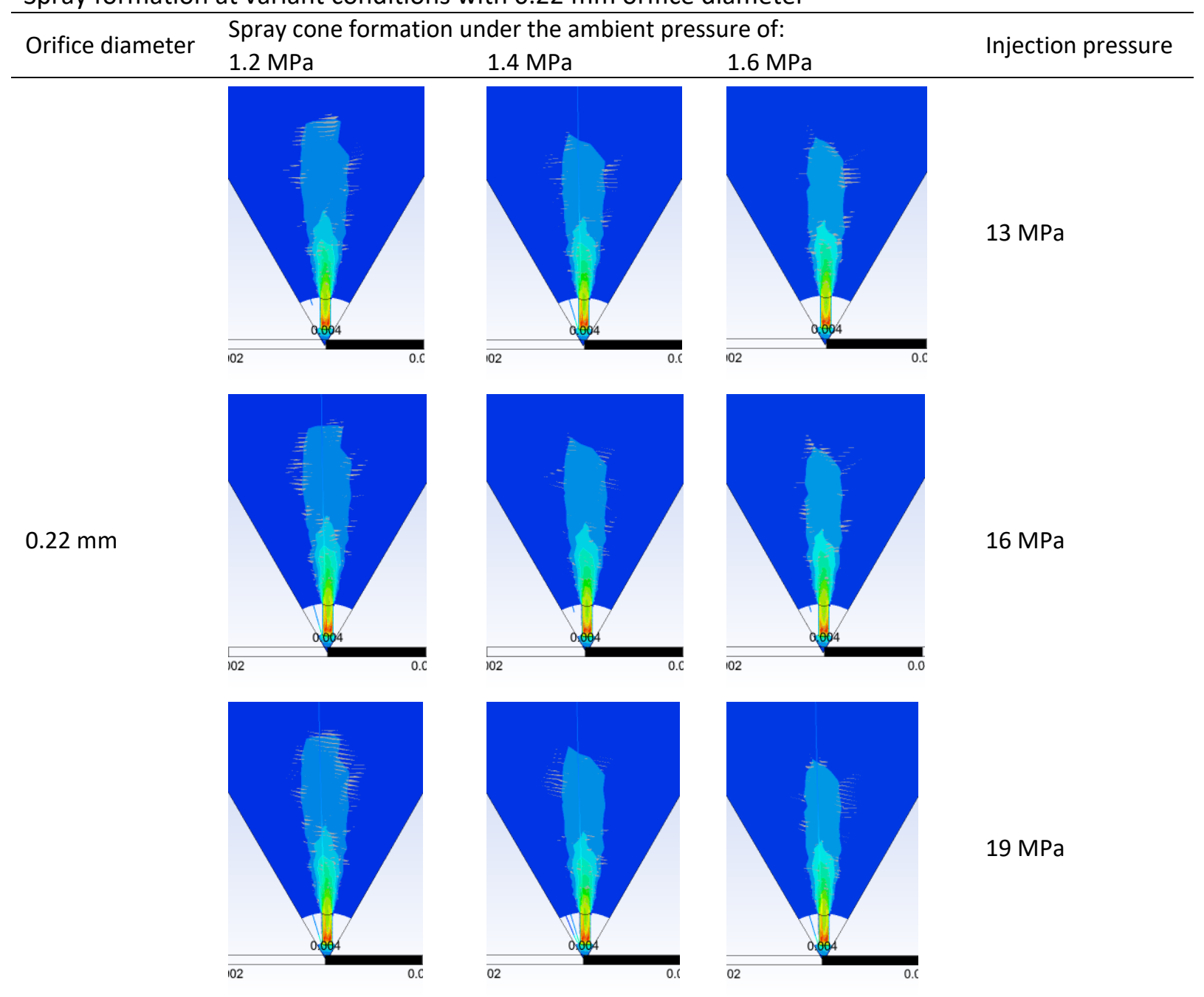




\section{Table 5}

Spray formation at variant conditions with $0.263 \mathrm{~mm}$ orifice diameter

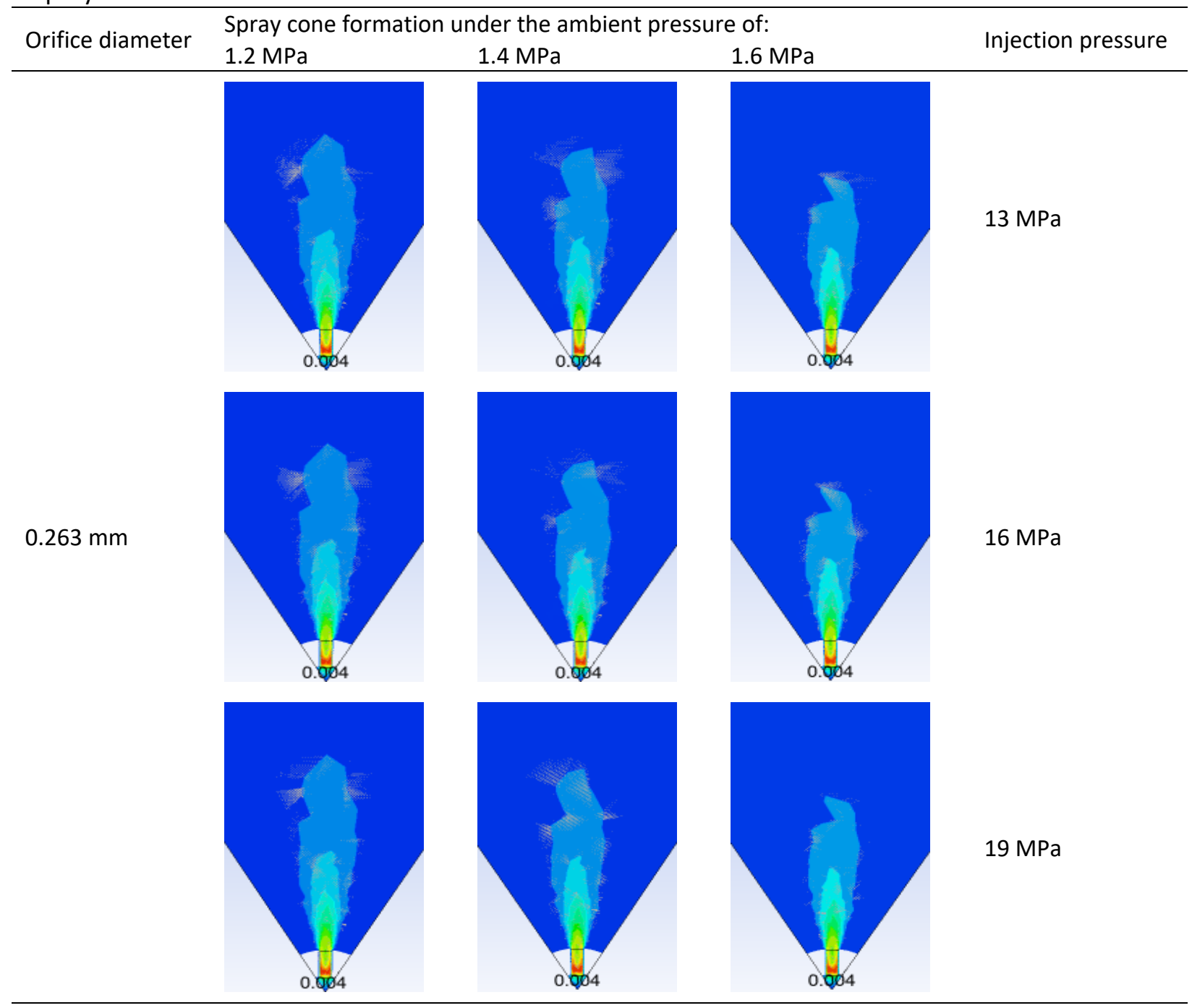

\section{Conclusions}

From this study, it has been exposed that the simulation flow of the fuel is injected through the nozzle spray prior to the combustion process that occurs inside the combustion chamber. The simulation work was stimulated by two different orifice diameters of $0.22 \mathrm{~mm}$ and $0.263 \mathrm{~mm}$. The injection pressures set for the nozzle were at three different values, $13 \mathrm{MPa}, 16 \mathrm{MPa}$ and $19 \mathrm{MPa}$. In addition, six different ambient pressures used inside the chamber, which are also the main parameters for this study: 0.6 MPa, 0.8 MPa, 1.0 MPa, 1.2 MPa, 1.4 MPa and 1.6 MPa.

This study confirmed that the ambient pressure had an impact on the size of the fuel droplet diameter. As it increases, the spray tends to evaporate and disperse easily, resulting in a wider spray angle formation. From this study, it was found that the $0263 \mathrm{~mm}$ orifice diameter has a slightly wider spray cone angle compared to $0.22 \mathrm{~mm}$ orifice diameter. Thus, we can conclude that the increasing of ambient pressure causes the spray cone angle increases. As for the spray penetration, it shows decreasing in length as the ambient pressure increases. This is caused by the high ambient pressure inside the combustion chamber prevent the spray to penetrate longer. The longer spray penetration observed when the ambient pressure was set at lower pressure. It seems that ambient pressure affected both spray cone angle and the spray penetration. 
I. High ambient pressure at larger orifice diameter cause increasing in spray cone angle.

II. High ambient pressure at lower injection pressure cause increasing in spray penetration.

\section{Acknowledgement}

The authors would like to thank the Ministry of Education Malaysia for supporting this research under Fundamental Research Grant Scheme FRGS/1/2019/TK10/UTHM/02/7 Vot K218 and also Research Fund Universiti Tun Hussein Onn Malaysia (B057) and Geran Penyelidikan Pascasiswazah (GPPS) vot. U749.

\section{References}

[1] Giakoumis, Evangelos G. "Diesel and spark ignition engines emissions and after-treatment control: research and advancements. " Energies 10, no. 11 (2017): 1882.

https://doi.org/10.3390/en10111882

[2] Hassan, Muhamad Najib, Amir Khalid, Norrizal Mustaffa, Nofrizalidris Darlis, Norrizam Jaat, Adiba Rhaodah Andsaler, and Akmal Nizam Mohammed. "Simulation of Biodiesel Sprays under High Ambient Temperature using Computational Fluid Dynamics." In Journal of Physics: Conference Series, vol. 1150, no. 1, p. 012063. IOP Publishing, 2019. https://doi.org/10.1088/1742-6596/1150/1/012063

[3] Jaat, N., A. Khalid, N. Mustaffa, F.H. Zulkifli, N.M. Sunar, R.S. Nursal, M.A.H. Mohamad, and D. Didane. "Analysis of injection pressure and high ambient density of biodiesel spray using computational fluid dynamics. "CFD Letters 11, no. 1 (2019): 28-39.

[4] Delvi, H.A., M. Faheem, A. Aabid, M.C. Math, and S.A. Khan. "Investigation of characteristics of spark ignition engine fuelled with ethanol-gasoline blends using iso-octane additive. " Journal of Advanced Research in Fluid Mechanics and Thermal Sciences 66, no. 1 (2020): 151-163.

[5] Hashim, Akasha, Amir Khalid, Norrizam Jaat, Azwan Sapit, Azahari Razali, and Akmal Nizam. "Analysis of high injection pressure and ambient temperature on biodiesel spray characteristics using computational fluid dynamics." In IOP Conference Series: Materials Science and Engineering, vol. 243, no. 1, p. 012049. IOP Publishing, 2017.

https://doi.org/10.1088/1757-899X/243/1/012049

[6] Khalid, Amir, Adiba Rhaodah Andsaler, Bukhari Manshoor, and Norrizam Jaat. "Effect of high pressure on the flow characteristics of injector using computational fluid dynamics (CFD)." ARPN Journal of Engineering and Applied Sciences 11, no. 12 (2016): 7503-7506.

[7] Khalid, Amir, Adiba Rhaodah Andsaler, and Norrizam Jaat. "Simulation and Modeling on Mixture Formation under Variant Condition and Injection Pressure of Biodiesel Spray." International Journal of Integrated Engineering 9, no. 3 (2017).

[8] Andsaler, Adiba Rhaodah, Amir Khalid, Nor Sharifhatul Adila Abdullah, Azwan Sapit, and Norrizam Jaat. "The effect of nozzle diameter, injection pressure and ambient temperature on spray characteristics in diesel engine." In Journal of Physics: Conference Series, vol. 822, no. 1, p. 012039. IOP Publishing, 2017. https://doi.org/10.1088/1742-6596/822/1/012039

[9] Nursal, Ridwan Saputra, Zakiman Zali, Shahril Jalil, Amir Khalid, and Syahrunniza Abd Hadi. "Experimental study of the bio-additives effects in biodiesel fuel on performance, emissions and combustions characteristics of diesel engine." ARPN J. Eng. Appl. Sci 12, no. 6 (2017): 1997-2005.

[10] Jalil, Shahril, Zamri Yusoff, Hairi Haizri Che Amat, and Ridwan Saputra Nursal. "Investigation on Performance and Emissions of a Single Cylinder Marine Diesel Engine Fuelled with Diesel and Crude Palm Biodiesel Oil." In Advancement in Emerging Technologies and Engineering Applications, pp. 189-201. Springer, Singapore, 2020. https://doi.org/10.1007/978-981-15-0002-2 20

[11] Khalid, Amir. "Effect of Ambient Temperature on Ignition Delay and Biodiesel Derived from Algae." International Journal of Integrated Engineering 10, no. 4 (2018): 43-48.

[12] Ahmed, CM Sabbir, Jiacheng Yang, Jin Y. Chen, Huanhuan Jiang, Cody Cullen, Georgios Karavalakis, and Ying-Hsuan Lin. "Toxicological responses in human airway epithelial cells (BEAS-2B) exposed to particulate matter emissions from gasoline fuels with varying aromatic and ethanol levels." Science of The Total Environment 706 (2020): 135732.

https://doi.org/10.1016/j.scitotenv.2019.135732 
[13] Awang, Mohd Naim, Zakiman Zali, Nor Ashimy Mohd Noor, and Ridwan Saputra Nursal. "Main Propulsion Marine Diesel Engine Condition Based Maintenance Monitoring Using Ultrasound Signal." In Advancement in Emerging Technologies and Engineering Applications, pp. 175-187. Springer, Singapore, 2020.

https://doi.org/10.1007/978-981-15-0002-2 19

[14] Zainol, Ismail, Z. M. Ahmad, S. N. Ridwan, Z. M. Zaifurizal, M. R. Dahalan, A. Kamal, and Zulzamri Salleh. "Carbon Emissions Measurement Using Portable Emission Device in Coastal Fishing Boats." In Advancement in Emerging Technologies and Engineering Applications, pp. 339-349. Springer, Singapore, 2020. https://doi.org/10.1007/978-981-15-0002-2 35

[15] Duronio, Francesco, Angelo De Vita, Alessandro Montanaro, and Carlo Villante. "Gasoline direct injection enginesA review of latest technologies and trends. Part 2." Fuel 265 (2020): 116947.

https://doi.org/10.1016/j.fuel.2019.116947

[16] Lee, Ziyoung, Taehoon Kim, Sungwook Park, and Suhan Park. "Review on spray, combustion, and emission characteristics of recent developed direct-injection spark ignition (DISI) engine system with multi-hole type injector." Fuel 259 (2020): 116209.

https://doi.org/10.1016/i.fuel.2019.116209

[17] Khalid, A., A. S. A. Tajuddin, N. Jaat, B. Manshoor, I. Zaman, S. A. A. Hadi, and R. S. Nursal. "Performance and emissions of diesel engine fuelled with preheated biodiesel fuel derived from crude palm, jatropha, and waste cooking oils." International Journal of Automotive and Mechanical Engineering 14 (2017): 4273-4284.

[18] Wu, Zengyang, Libing Wang, Jihad A. Badra, William L. Roberts, and Tiegang Fang. "GDI fuel sprays of light naphtha, PRF95 and gasoline using a piezoelectric injector under different ambient pressures." Fuel 223 (2018): $294-311$. https://doi.org/10.1016/j.fuel.2018.03.009

[19] Zhang, Wenbin, Zhou Zhang, Xiao Ma, Omar I. Awad, Yanfei Li, Shijin Shuai, and Hongming Xu. "Impact of injector tip deposits on gasoline direct injection engine combustion, fuel economy and emissions." Applied Energy 262 (2020): 114538.

https://doi.org/10.1016/i.apenergy.2020.114538

[20] Hassen, Nasir Salim, and Nor Azwadi Che Sidik. "Laboratory Investigation of Nozzle Type, Size and Pressure Effects on Spray Distribution." Journal of Advanced Research in Fluid Mechanics and Thermal Sciences 61, no. 1 (2019): 140-146.

[21] Khalid, Amir, Shahrin Hisham Amirnordin, Uthayakumar Vasuthavan, Azian Hariri, and Mas Fawzi. "Spray Formation in the Multi-Hole Nozzle of Twin-Fluid Atomizers." Journal of Advanced Research in Fluid Mechanics and Thermal Sciences 53, no. 1 (2019): 75-81.

[22] Qian, Yong, Jianping Wang, Zilong Li, Chenxu Jiang, Zhuoyao He, Liang Yu, and Xingcai Lu. "Improvement of combustion performance and emissions in a gasoline direct injection (GDI) engine by modulation of fuel volatility." Fuel 268 (2020): 117369.

https://doi.org/10.1016/i.fuel.2020.117369

[23] Frhan, N.K., A. Sapit, M.A. Razali, M.F. Hushim, A.N. Mohammed, B. Manshoor, and A. Khalid. "Numerical CFD analysis of a direct injection (DI) four strokes single cylinder diesel engine at different compression ratios. " CFD Letters 10, no. 2 (2018): 28-37.

[24] Nursal, Ridwan Saputra, Nor Isha Nordin, Marzuki Mohammad, M. Afandi, A. Hamid, M. N. Awang, and A. A. M. Ariffin. "Investigation on resistance effects through towing test and CFD analysis on catamaran boat hull form." ARPN J Eng App/ Sci 12, no. 4 (2017): 1334-1343.

[25] El-Faroug, Musaab O., Fuwu Yan, Maji Luo, and Richard Fiifi Turkson. "Spark ignition engine combustion, performance and emission products from hydrous ethanol and its blends with gasoline." Energies 9, no. 12 (2016): 984.

https://doi.org/10.3390/en9120984

[26] Zhuang, Yuan, Yongfei Ma, Yejian Qian, Qin Teng, and Chunmei Wang. "Effects of ethanol injection strategies on mixture formation and combustion process in an ethanol direct injection (EDI) plus gasoline port injection (GPI) spark-ignition engine." Fuel 268 (2020): 117346.

https://doi.org/10.1016/j.fuel.2020.117346

[27] Nursal, Ridwan Saputra, Zakiman Zali, Hairi Haizri Che Amat, Syed Amear Syed Ariffin, and Amir Khalid. "Comparative study of the performance and exhaust gas emissions of biodiesels derived from three different feedstocks with diesel on marine auxiliary diesel engine." ARPN J. Eng. Appl. Sci 12, no. 6 (2017): 2017-2028.

[28] Agarwal, Avinash Kumar. "Biofuels (alcohols and biodiesel) applications as fuels for internal combustion engines." Progress in energy and combustion science 33, no. 3 (2007): 233-271. https://doi.org/10.1016/j.pecs.2006.08.003

[29] Mamat, R., M. S. M. Sani, K. Sudhakar, Asep Kadarohman, and R. E. Sardjono. "An overview of Higher alcohol and biodiesel as alternative fuels in engines." Energy Reports 5 (2019): 467-479. 
https://doi.org/10.1016/j.egyr.2019.04.009

[30] Zheng, Yi. "Simulations and experiments of fuel injection, mixing and combustion in DI gasoline engines. " Ph. D dissert., Wayne State University, 2013.

[31] Sovani, S. D., E. Chou, P. E. Sojka, J. P. Gore, W. A. Eckerle, and J. D. Crofts. "High pressure effervescent atomization: effect of ambient pressure on spray cone angle." Fuel 80, no. 3 (2001): 427-435. https://doi.org/10.1016/S0016-2361(00)00105-8

[32] Feng, Zehao, Cheng Zhan, Chenglong Tang, Ke Yang, and Zuohua Huang. "Experimental investigation on spray and atomization characteristics of diesel/gasoline/ethanol blends in high pressure common rail injection system." Energy 112 (2016): 549-561.

https://doi.org/10.1016/i.energy.2016.06.131

[33] Baddu, Nuriati, Amir Khalid, Dahrum Samsudin, Izzuddin Zaman, and Bukhari Manshoor. "Investigation of flame characteristics of ethanol-gasoline blends combustion using constant volume chamber." In MATEC Web of Conferences, vol. 78, p. 01030. EDP Sciences, 2016. https://doi.org/10.1051/matecconf/20167801030

[34] Sapee, S. "Computational Fluid Dynamics Study on Droplet Size of Kerosene Fuel." Journal of Advanced Research in Fluid Mechanics and Thermal Sciences 16, no. 1 (2015): 1-14.

[35] Shi, Lei, Changwei Ji, Shuofeng Wang, Xiaoyu Cong, Teng Su, and Cheng Shi. "Impacts of dimethyl ether enrichment and various injection strategies on combustion and emissions of direct injection gasoline engines in the lean-burn condition." Fuel 254 (2019): 115636

https://doi.org/10.1016/i.fuel.2019.115636 